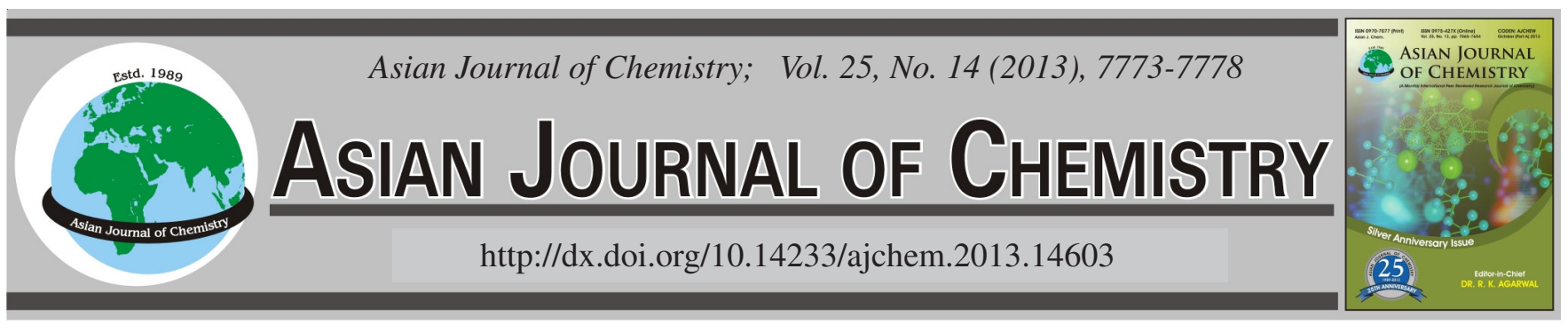

\title{
Design, Preparation and Characterization of Novel Shape Memory Porous Poly(urethane-urea) Scaffold for Non-Union
}

\author{
Meina Huang ${ }^{1,2, *}$, Yuanliang Wang ${ }^{3}$, Yanfeng LuO $^{2}$ and Fusheng Pan ${ }^{1, *}$
}

\begin{abstract}
${ }^{1}$ National Engineering Research Center for Magnesium Alloy; College of Materials Science and Engineering, Chongqing University, Chongqing 400030, P.R. China

${ }^{2}$ College of Mechanical Engineering, Chongqing Technology and Business University, Chongqing 400067, P.R. China

${ }^{3}$ Key Laboratory of Biorheological Science and Technology, Ministry of Education, China; Research Center of Bioinspired Material Science and Engineering, College of Bioengineering, Chongqing University, Chongqing 400030, P.R. China
\end{abstract}

*Corresponding authors: Tel: +86 15320437026; E-mail: fspan@cqu.edu.cn; meinahuang1982@163.com

\begin{abstract}
A novel shape memory porous scaffold was prepared by copolymerization and emulsion copolymerization method. Initially, isocyanate terminated prepolymer was prepared from reaction of HO-terminated poly (lactide-co-p-dioxanone) with hexamethylene diisocyanate for $3 \mathrm{~h}$ at $70 \sim 75^{\circ} \mathrm{C}$. Then the excess NCO reacted with butanediamine below $5^{\circ} \mathrm{C}$, aiming to realize chain extension. During this process, the porogen $\mathrm{NaCl} / \mathrm{PVP}$ was introduced. The emulsion was dried by vacuum and the dried materials were compressed to special shape and then salt leaching method was used to prepare porous scaffold. The pore structure and pore size were characterized by scanning electron microscopy and the porosity was measured with liquid substitution method and connectivity was measured by calculating the ratio of drip mass to time. Mechanical performance and shape memory property were also studied. These results denoted that pore size and porosity have significant influence on the mechanical and shape memory properties of shape memory poly(urethane-urea). However, the shape memory property is as high as $52 \% \sim 80 \%$ and mechanical modulus is $100-350 \mathrm{MPa}$, similar to the natural bone, which is beneficial to treatment of the non-union.
\end{abstract}

Key Words: Smart polymers, Porous scaffold, Shape memory poly(urethane-urea), Non-union, Emulsion copolymerization.

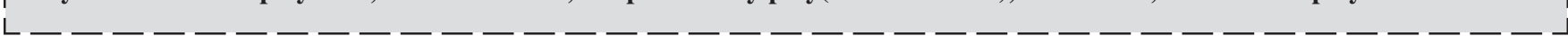

\section{INTRODUCTION}

Shape memory polymer is an emerging class of smart polymer, which can change its shape under the external conditions, such as thermal and electrical stimulation and have a great potential for biomedical applications, especially in the area of minimally invasive surgery ${ }^{1}$. One trend of biomedical polymer is to realize shape memory property and biodegradability $^{2}$. Biodegradable shape memory poly(urethane-urea), attributing to its biodegradability and biocompatiblity has attracted growing interest in recent years ${ }^{3-6}$. Fig. 1 shows the schematic representation of the shape memory principle of shape memory poly(urethane-urea). It was based on the thermo-elastic phase transformation and its reversal at the temperature above and below $\mathrm{T}_{\mathrm{g}}$. Its glass transition temperature can be set up around body temperature, thus the shape memory poly(urethane-urea) will have wide applications in the tissue engineering.

Polylactic acid-based polymer is a kind of popular biomedical material, since polylactic acid (PLA) has biodegradability and shape memory property. Moreover, glycolic acid was incorporated into polylactic acid, which exhibited the fastened and controllable degradation rate due to the better hydrophilicity of poly(glycolic acid) (PGA) ${ }^{7}$. In addition, poly(ethylene glycol) (PEG) was copolymerized with polylactic acid and the obtained block copolymer PLA-PEG-PLA, compared to polylactic acid, showed the improved flexibility, because of introduction of ether bond. Based on above information, the combination of glycolic acid and ethylene glycol, together with polylactic acid will hopefully create copolymer that possesses many advantages. $p$-Dioxanone (PDO) is in structure a cyclic compound condensed from one molecule of glycolic acid and one molecule of ethylene glycol, which makes $p$-dioxanone have good flexibility.

Moreover, the $\mathrm{T}_{\mathrm{g}}$ of PPDO (the polymer of $p$-dioxanone) is only about $-10{ }^{\circ} \mathrm{C}^{8}$, while the $\mathrm{T}_{\mathrm{g}}$ of polylactic acid is about 50 60 ${ }^{\circ} \mathrm{C}^{9}$, which is beneficial to copolymerize the HO-P(LA$\mathrm{PDO})-\mathrm{OH}$ (soft segment) with different $\mathrm{T}_{\mathrm{g}}$ and then regulate the shape memory temperature of poly (urethane-urea).

In the bone tissue engineering, non-union may have severe consequences, particularly when combined with other 
post-traumatic sequelae such as tendon adhesions, reflex sympathetic dystrophy and infection, among others ${ }^{10-12}$. Nonunion and/or those with bone loss require biological treatment, such as the excision of the pathological non-union site or the creation of new bone substance by using of distraction techniques. The treatment of choice that meets both the biological and mechanical requirements is external fixation, in as much as it has an extremely low septic complication rate and the mechanical environment can be automatically varied or programmed based on the requirements ${ }^{13}$.

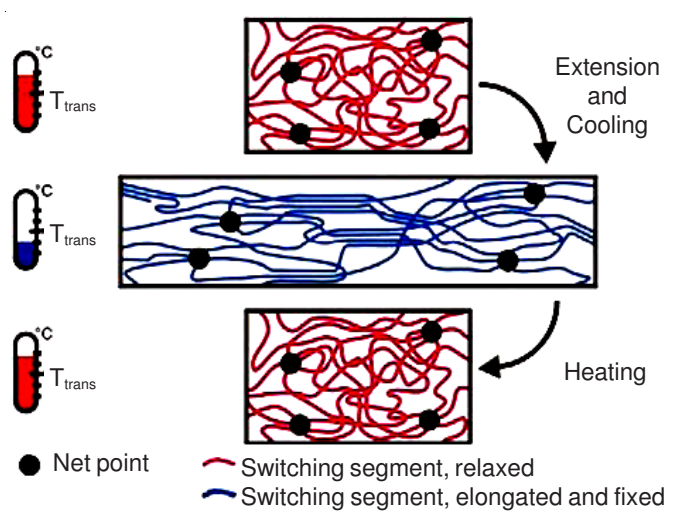

Shape B

Shape A

Shape B

Fig. 1. Schematic representation of shape memory tests

The biodegradable poly(urethane-urea) can realize the biological and mechanical requirements, because of its biodegradability and shape memory properties. In the repair process, the scaffold with specific temporary shape can be easily put into the bone defect site, then it can recover to original shape (permanent shape) under the external conditions and fill the gap, which can eliminate the energy barrier of the osteoblast proliferation. In this paper, we prepared the porous shape memory scaffold with small pore via emulsion method. The small pore is favour of blood supply and interchange of energy by the small pore, which result in the vascularization and is hopeful to treat non-union that caused by lack of flood and having an energy barrier between implant and tissue.

\section{EXPERIMENTAL}

Hexamethylene diisocyanate and butanediamine are purchased from Sigma-Aldrich Corporation. Toluene, isopropanol, $\mathrm{NaCl}$, polyvinylpyrrolidone and Span 60 are purchased from Chongqing Oriental Chemical Factory. The moisture in hexamethylene diisocyanate and toluene was removed by reacting with $\mathrm{CaH}_{2}$ as less as $0.01 \%$. D, L-lactide (LA) was synthesized and purified in our laboratory, with a purity of higher than $99.9 \%$. p-Dioxanone is supplied by Jinan Biotechnology Corporation.

Synthesis of prepolymer from HO-P(LA-PDO)-OH and hexamethylene diisocyanate: Firstly, HO-P(LA-PDO)$\mathrm{OH}$ was synthesized by melt ring-opening polymerization of $\mathrm{D}$, L-lactide (LA) and $p$-dioxanone (PDO) with $\mathrm{Sn}(\mathrm{Oct})_{2}$ as initiator and ethylene glycol as $c o$-initiator at $140{ }^{\circ} \mathrm{C}$ for $24 \mathrm{~h}$ under vacuum (The first step of Scheme-I). The obtained copolymer was purified through co-precipitation in chloroform- $n$-absolute ethyl alcohol system at room temperature. The purified copolymer was vacuum dried at room temperature
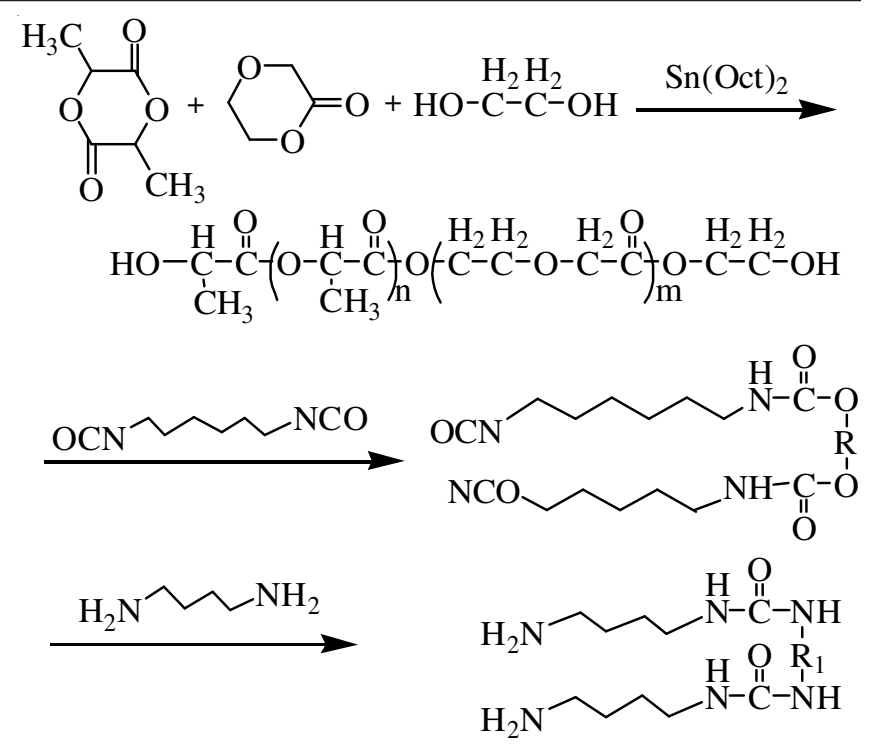

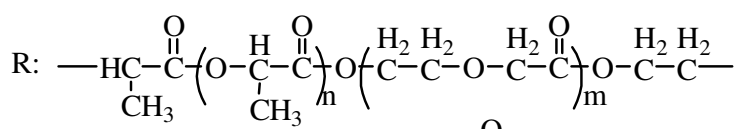

$$
\begin{aligned}
& \mathrm{R}_{\mathrm{R}} \text { : }
\end{aligned}
$$

for $48 \mathrm{~h}$. In the process, the number average molecular weight $\left(\overline{\mathrm{M}}_{\mathrm{n}}\right)$ of HO-P (LA-PDO)-OH can be controlled by regulating the ratio of lactic acid to $p$-dioxanone and the content of ethylene glycol.

Secondly, predetermined amounts of HO-P (LA-PDO)$\mathrm{OH}$, hexamethylene diisocyanate, $\mathrm{Sn}(\mathrm{Oct})_{2}$ and anhydrous toluene were added into a $250 \mathrm{~mL}$ three-neck round-bottomed flask with the thermometer, magnetic stirrer and drying tube. In addition, nitrogen with a purity of $99.99 \%$ was continuously introduced into the flask through the above drying tube. After $3 \mathrm{~h}$ of reaction at $70 \sim 75^{\circ} \mathrm{C}$, the prepolymer (OCN-HDI-P (LAPDO)-HDI-NCO) was obtained (the second step of Scheme-I).

Preparation of shape memory porous scaffold with emulsion copolymerization method: Porous scaffold was prepared by emulsion copolymerization and leaching salt technique in the chain extension reaction (the third step of SchemeI) as follows. Firstly, a $10 \mathrm{wt} \%$ prepolymer toluene solution was produced and then $1 \mathrm{wt} \%$ span was added to produce the oil phase. Secondly, $\mathrm{NaCl} /$ polyvinylpyrrolidone water solution and butanediamine/isopropanol solution formed the water phase. Thirdly, water phase was dropped slowly into the oil phase and stirred for $2 \mathrm{~h}$ below $5^{\circ} \mathrm{C}$ to stabilize the emulsion. Fourthly, the emulsion was dried by vacuum drying and then the dried material was placed in a disk mold $(\mathrm{D}=12 \mathrm{~mm})$ and pressed at $16 \mathrm{MPa}$ for $3 \mathrm{~min}$ at room temperature using a tablet machine to yield solid disks. At last, $\mathrm{NaCl} /$ polyvinylpyrrolidone was subsequently removed by leaching at room temperature and ultrasound for $48 \mathrm{~h}$ and then the porous scaffold was produced by freeze-drying (freezing at $-80{ }^{\circ} \mathrm{C}$ and then vacuum drying at $-40^{\circ} \mathrm{C}$ ). The effects of the weight ratio of 
$\mathrm{NaCl} /$ polyvinylpyrrolidone to shape memory poly(urethaneurea), ratio of $\mathrm{NaCl} /$ polyvinylpyrrolidone, were examined.

The porous scaffold was dissolved in $\mathrm{CHCl}_{3}$ for FTIR measurement (the solution $15 \mathrm{mg} / \mathrm{mL}$ was added dropwise on the $\mathrm{KBr}$ flake) and $\mathrm{CDCl}_{3}$ for ${ }^{1} \mathrm{H} \mathrm{NMR}$ (the concentration of solution is $30 \mathrm{mg} / \mathrm{mL} .300 \mathrm{~Hz}$ ). Fig. 2 is FTIR of shape memory poly(urethane-urea), which includes following characteristic peaks: $3507.99 \mathrm{~cm}^{-1}[\mathrm{v}(\mathrm{OH})$ in hydroxyl terminated], 2996 $\mathrm{cm}^{-1}, 2882 \mathrm{~cm}^{-1}\left[\mathrm{v}(\mathrm{CH})\right.$ in alkyl], $1756.14 \mathrm{~cm}^{-1}[\mathrm{v}(\mathrm{C}=\mathrm{O})$ in carbonyl group], $1455 \mathrm{~cm}^{-1}$ [ $\delta(\mathrm{C}-\mathrm{H})$ in methane and methylene], $1382 \mathrm{~cm}^{-1}\left[\delta(\mathrm{C}-\mathrm{H})\right.$ in methyl], $1587.04 \mathrm{~cm}^{-1}[\delta(\mathrm{N}-\mathrm{H})$ in $-\mathrm{CO}-$ NH-], $1618.43 \mathrm{~cm}^{-1}, 1675 \mathrm{~cm}^{-1}$ [ $\delta(\mathrm{C}=\mathrm{O})$ in -NH-CO-NH- and -CO-NH-, respectively], $3333.96 \mathrm{~cm}^{-1}\left[\delta(\mathrm{N}-\mathrm{H})\right.$ in $\left.\mathrm{NH}_{2}\right]$. Fig. 3 is ${ }^{1} \mathrm{H}$ NMR of shape memory poly(urethane-urea) $(300 \mathrm{MHz}$, $\mathrm{CDCl}_{3}$ ), which shows the characteristic peaks: 5.0 5.2 ppm (-CH- in polylactic acid segment, c in Fig. 3), 3.4 ppm (-CH ${ }_{2}^{-}$ in -O- $\mathrm{CH}_{2}-\mathrm{CH}_{2}-\mathrm{O}-\mathrm{CO}$ - of $p$-dioxanone segment, $\left.\mathrm{f}\right), 1.456 \sim$ $1.572 \mathrm{ppm}$ (-CH${ }_{3}$ - in polylactic acid segment, d), 4.12 4.40 ppm $\left(-\mathrm{CH}_{2}-\right.$ in $-\mathrm{O}-\mathrm{CH}_{2}-\mathrm{O}-\mathrm{CH}_{2}$ and $-\mathrm{O}-\mathrm{CH}_{2}-\mathrm{O}-\mathrm{CH}_{2}-\mathrm{CH}_{2}-\mathrm{O}-$ $\mathrm{CO}$ - of $p$-dioxanone segment, e), $3.86 \mathrm{ppm}\left(-\mathrm{CH}_{2}\right.$ - in the EG connected with $-\mathrm{OH}, \mathrm{h}), 4.48 \mathrm{ppm}\left(-\mathrm{CH}_{2}\right.$ - in the ethylene glycol connected with -OCO-), 5.751 ppm (-NH- in -CO-NH$\mathrm{CO}-$, b) and 7.4ppm (-NH- in -CO-NH-, a).

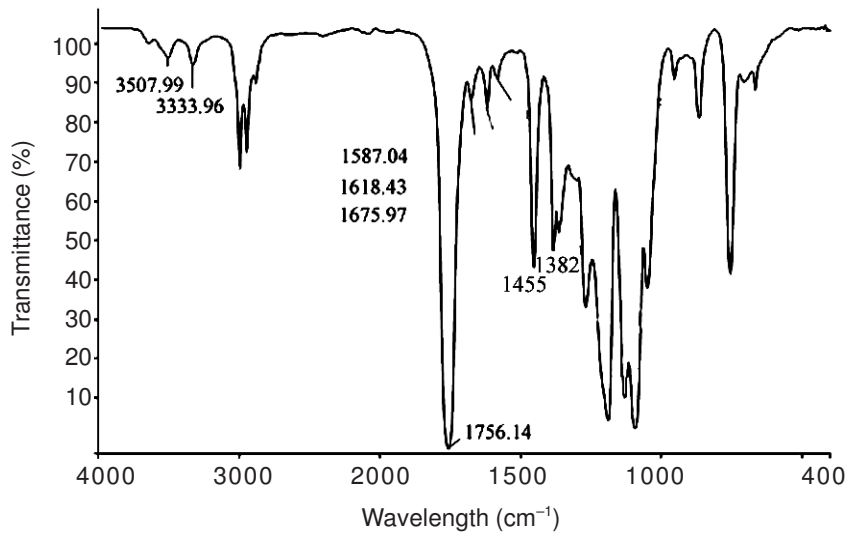

Fig. 2. FTIR spectra of poly (urethane-urea)

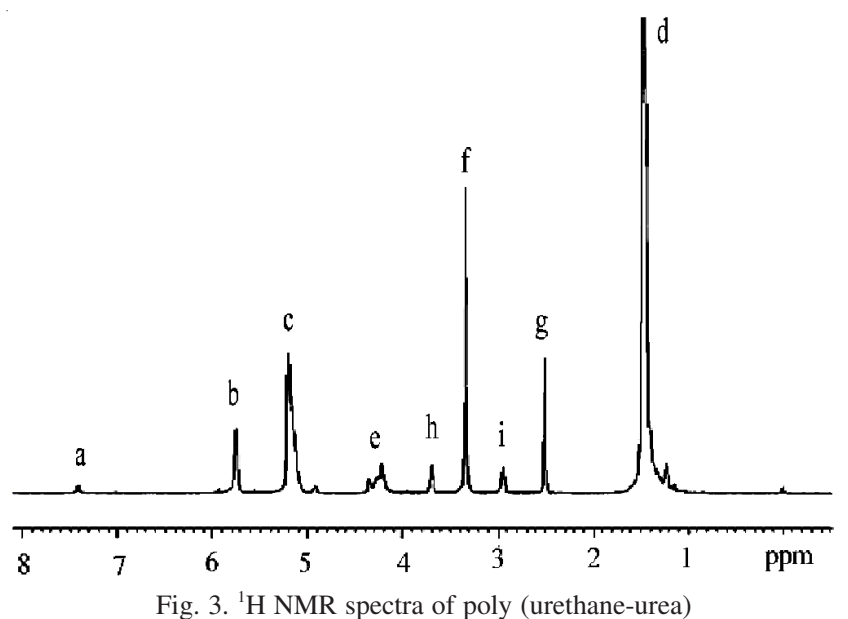

The FTIR and ${ }^{1} \mathrm{H}$ NMR measurement indicated that the structure of shape memory poly(urethane-urea) from emulsion method is same with the shape memory poly(urethane-urea).

Preparation of shape memory porous scaffold with the freeze-drying method: Poly (urethane-urea) was dissolved in 1,4-dioxane in $2 \mathrm{~g} / \mathrm{mL}$ solution, which lasted for $24 \mathrm{~h}$ for completely dissolving. The solution was poured into a Teflon mold $[\Phi 9 \times 25,(\mathrm{D}=9 \mathrm{~mm}, \mathrm{~L}=25 \mathrm{~mm})]$ and then it was frozen at $-80{ }^{\circ} \mathrm{C}$ for $0.5 \mathrm{~h}$ for solidifying. At last, the mold with shape memory poly(urethane-urea) was put into the vacuum freeze drier (vacuum degree: $<1.2 \mathrm{P}, \mathrm{T}:<-45^{\circ} \mathrm{C}$ ) for $24 \mathrm{~h}-48 \mathrm{~h}$.

The porous scaffold, fabricated with freeze-drying method, was the control of that fabricated with emulsion method.

Characterization of the porous scaffold: The porous scaffold was characterized by scaning electron microscopy, mechanical property, shape memory property and porosity, connectivity. The porous structure and pore size was observed by TESCAN VEGA $\pi$ LMU SEM (Pretreatment: gold sputtering). The compressive strength and modulus were measured on the Instron 1011 universal material testing machine as the loading rate was $0.5 \mathrm{~mm} / \mathrm{min}$. The size of the cylindroid porous scaffold is $\Phi 9 \times 15(\mathrm{D}=9 \mathrm{~mm}, \mathrm{~L}=15 \mathrm{~mm})$.

The shape memory property of shape memory poly(urethane-urea) was measured by shape fixation rate $\left(R_{f}\right)$, shape deformation rate $\left(R_{d}\right)$ and shape recovery rate $\left(R_{r}\right)$. The shape memory poly(urethane-urea) film (the original length is $\mathrm{L}_{0}$ ) can be easily deformed under external force at $\mathrm{T}_{\mathrm{g}}+15^{\circ} \mathrm{C}$ to $\mathrm{L}_{1}$ and then it was kept at $\mathrm{T}_{\mathrm{g}}-15^{\circ} \mathrm{C}$ for 5 min and unloaded, when the length of shape memory poly(urethane-urea) film to $\mathrm{L}_{2}$. At last, shape memory poly(urethane-urea) can change to the permanent shape $\left(\mathrm{L}_{3}\right)$ under $\mathrm{T}_{\mathrm{g}}+15^{\circ} \mathrm{C}$ from its temporary shape $\left(\mathrm{L}_{2}\right)$. Permanent shape of the porous scaffold is cylindroid and the size is $\Phi 9 \times 15(\mathrm{D}=9 \mathrm{~mm}, \mathrm{~L}=15 \mathrm{~mm})$.

$$
\begin{gathered}
\mathrm{R}_{\mathrm{f}}(\%)=\frac{\mathrm{L}_{2}-\mathrm{L}_{0}}{\mathrm{~L}_{1}-\mathrm{L}_{0}} \times 100 \% \\
\mathrm{R}_{\mathrm{r}}(\%)=\frac{\mathrm{L}_{2}-\mathrm{L}_{3}}{\mathrm{~L}_{2}-\mathrm{L}_{0}} \times 100 \% \\
\mathrm{R}_{\mathrm{d}}(\%)=\frac{\mathrm{L}_{2}}{\mathrm{~L}_{0}} \times 100 \%
\end{gathered}
$$

Glass transition temperature $\left(\mathrm{T}_{\mathrm{g}}\right)$ was determined by NETZSCH STA 449C differential scanning calorimetry (DSC) in a $50 \mathrm{~mL} / \mathrm{min}$ flow of $\mathrm{N}_{2}$ at a heating rate of $20{ }^{\circ} \mathrm{C} / \mathrm{min}$ ranging from $-50{ }^{\circ} \mathrm{C}$ to $300{ }^{\circ} \mathrm{C}$. (Fig. 4).

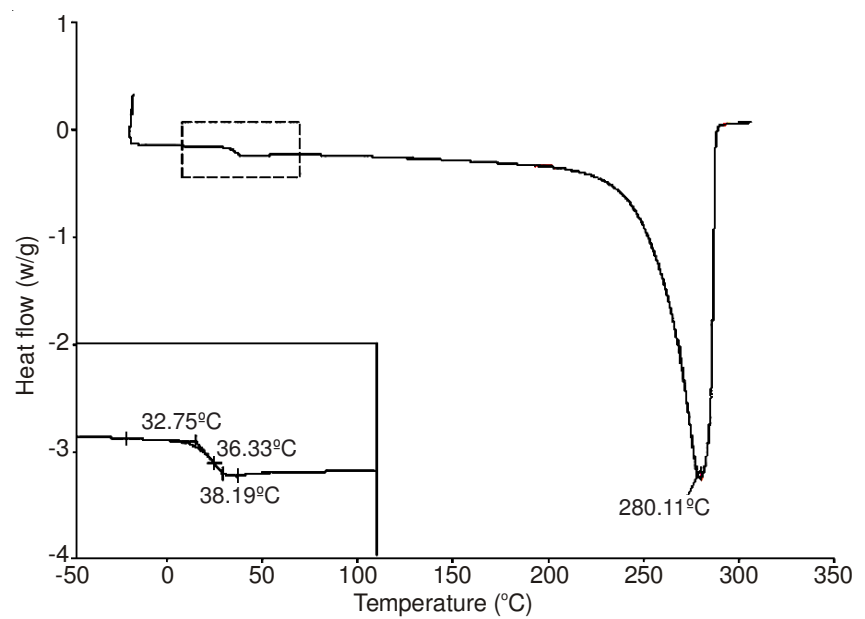

Fig. 4. DSC curve of poly (urethane-urea 
Measurement of porosity and connectivity: Porosity was measured by liquid substitution method. The liquid used in this study was isopropanol. The porosity was calculated by the formulae:

$$
\varepsilon=\left(\mathrm{V}_{1}-\mathrm{V}_{3}\right) /\left(\mathrm{V}_{2}-\mathrm{V}_{1}\right)
$$

where: $\varepsilon$, the porosity of scaffold; $V_{1}$, the volume of isopropanol before the scaffold was put in; $V_{2}$, the volume of liquid after the scaffold was put in; $V_{3}$, the volume of isopropanol after the liquid was pressed into the pore of the sample and the sample was taken out of the liquid.

The connectivity (c) was measured by a simple experiment. The porous scaffold was fixed by a round frame and a small glass dish $[\Phi 15 \times 15(\mathrm{D}=15 \mathrm{~mm}, \mathrm{H}=15 \mathrm{~mm})]$ was put under the round frame. After the isopropanol was dropwized on the porous scaffold, the time $\left[\mathrm{t}_{1}-\mathrm{t}_{0}(\mathrm{~min})\right]$ was started to be counted and the mass of isopropanol [m (mg)], in the glass dish, was weight. The connectivity was calculated by the following formulae:

$$
\mathrm{c}=\mathrm{m}\left(\mathrm{t}_{1}-\mathrm{t}_{0}\right)
$$

\section{RESULTS AND DISCUSSION}

Scanning electron microscopy: Fig. 5 shows scanning electron microscope images of the porous structure of shape memory poly(urethane-urea) with emulsion method (Fig. 5a, porosity is $52 \%$ ) and freeze-drying method (Fig. 5b, porosity is $68 \%$ ). It was evident that the porous scaffold structure and pore structure are different. The pores in Fig. 5a are smaller than that in Fig. $5 \mathrm{~b}$ and the structure of the porous scaffold in Fig. 5a is more compact than that in Fig. 5b. Moreover, the thin wall was found in Fig. 5a, while the thick wall in Fig. 5b. The SEM micrographs indicate that the porous scaffold made by emulsion method is completely different from those made by the freeze-drying method.

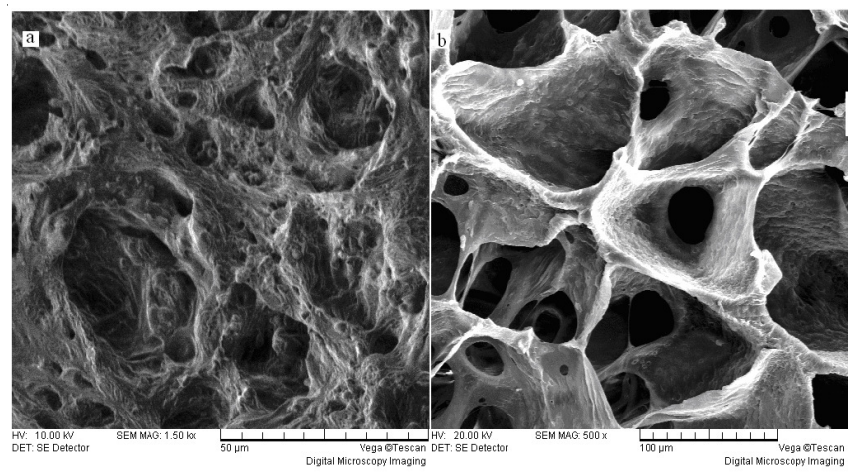

Fig. 5. SEM of porous poly (urethane-urea) scaffolds; (Note: a is fabricated with emulasion method; $b$ is fabricated with freeze-drying method)

The SEM shows that the size of the porous scaffold from emulsion method is different from the porous scaffold in another study (the size is about 100-250 $\mu \mathrm{m}$ ), however, previous study showed small pore in porous scaffold is beneficial to the transfer of blood and energy, while the bigger pore is beneficial to the cell growth. Literature ${ }^{12}$ reported lack of blood supply is the important inducement of the non-union, which possible is solved by employing the porous scaffold with small pores.
Pore properties: Porosity, pore size and connectivity are important parameters for porous scaffold employed in tissue engineering. Fig. 6 shows the change of porosity and pore size of the porous scaffold from emulsion with variation of content of porogen and the ratio of $\mathrm{NaCl} /$ polyvinylpyrrolidone. It is shown that when the weight ratio of porogen to shape memory poly(urethane-urea) increased from $0.5 / 1$ (scaffold 1-3) to 1/1(scaffold 4-6), the porosity, pore size increased significantly. In addition, it indicated that when the content of polyvinylpyrrolidone increased, the two parameters would increase rapidly. Fig. 7 shows that the connectivity increased significantly with increasing of the content of polyvinylpyrrolidone. The results showed that in the study, different porous scaffolds were made by using a new method and the porosity, connectivity and pore size can be regulated by changing the content of porogen $(\mathrm{NaCl} /$ polyvinylpyrrolidone) and the ratio of water phase to oil phase. In addition, the results showed that pore size was less than 100 $\mu \mathrm{m}$, which is not in the scope between $100 \mu \mathrm{m}$ and $250 \mu \mathrm{m}$, which could be attributed to the preparing method. In the emulsion method, the porogen was solved in the solution, so it is at the molecular level. When the water phase with porogen $(\mathrm{NaCl} /$ PVP) was added dropwise into the oil phase, the small particles were formed, the porogen as disperse phase was embedded in the continuous phase, shape memory poly(urethane-urea) and then the disperse phase was dissolved under ultrasound and water.

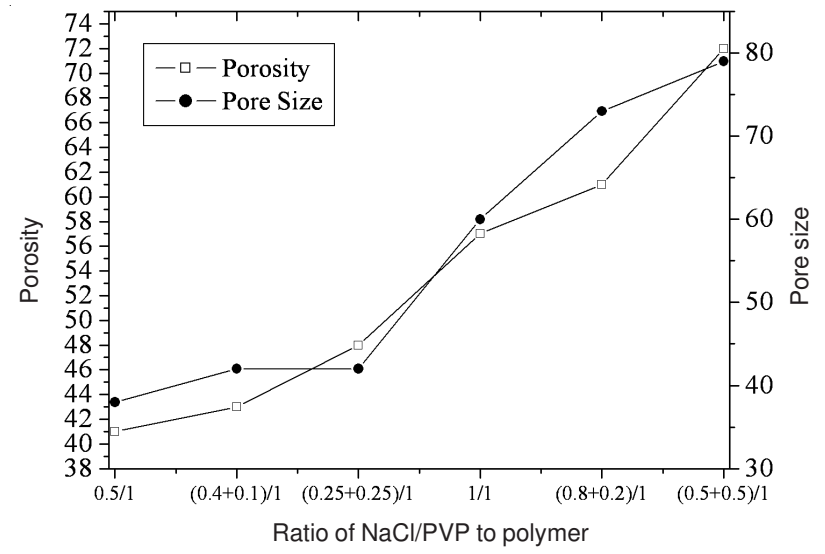

Fig. 6. Effect of ratio of $\mathrm{NaCl} / \mathrm{PVP}$ and weight ratio of porogen/SMPUU on porosity and pore size

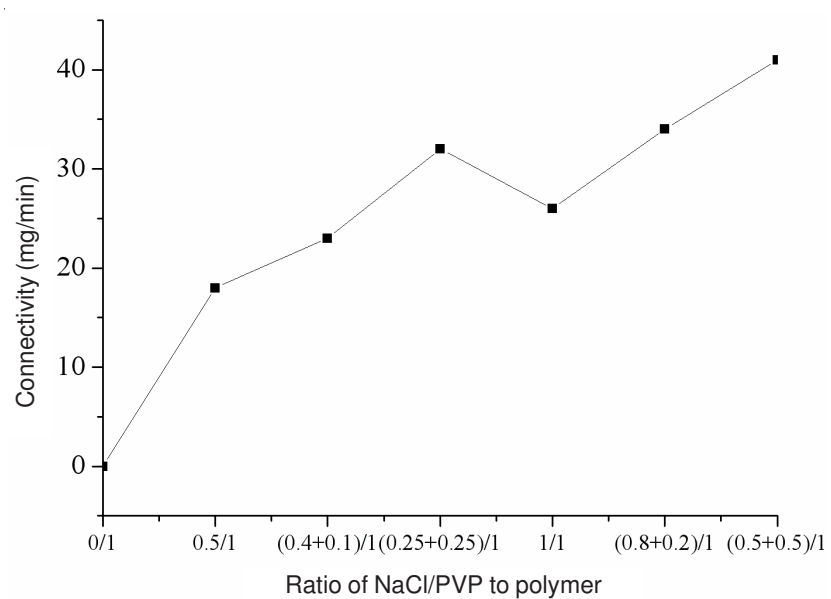

Fig. 7. Effect of ratio of $\mathrm{NaCl} / \mathrm{PVP}$ and weight ratio of porogen/SMPUU on connectivity of porous SMPUU 
Fig. 7 shows that the content of $\mathrm{NaCl} /$ polyvinylpyrrolidone and ratio of $\mathrm{NaCl}$ to polyvinylpyrrolidone are two most important influence factors of pore size and porosity, connectivity. The polyvinylpyrrolidone is a high molecular weight water-soluble polymer; it can be solved in water/toluene mixture and form the shape memory poly(urethane-urea)/polyvinylpyrrolidone polymer network staggered-structure. After polyvinylpyrrolidone dissolving in the water, the connected channels were left in the shape memory poly(urethane-urea) scaffold, which is the key factor to increase the connectivity. In addition, the polyvinylpyrrolidone has a certain viscosity in the mixture, which makes the polymer slowly expanded uniform at drying process and formed the uniform pores.

Mechanical property: The compressive strength and compressive modulus of porous shape memory poly(urethaneurea) from emulsion method were shown in Fig. 8. The ultimate compressive modulus of porous shape memory poly(urethaneurea) is up to $330 \mathrm{MPa}$, which is about the Young's modulus of canellous bone $(0.05-0.5 \mathrm{GPa})$ and far lower than that of poly (urethane-urea) (1234 MPa).

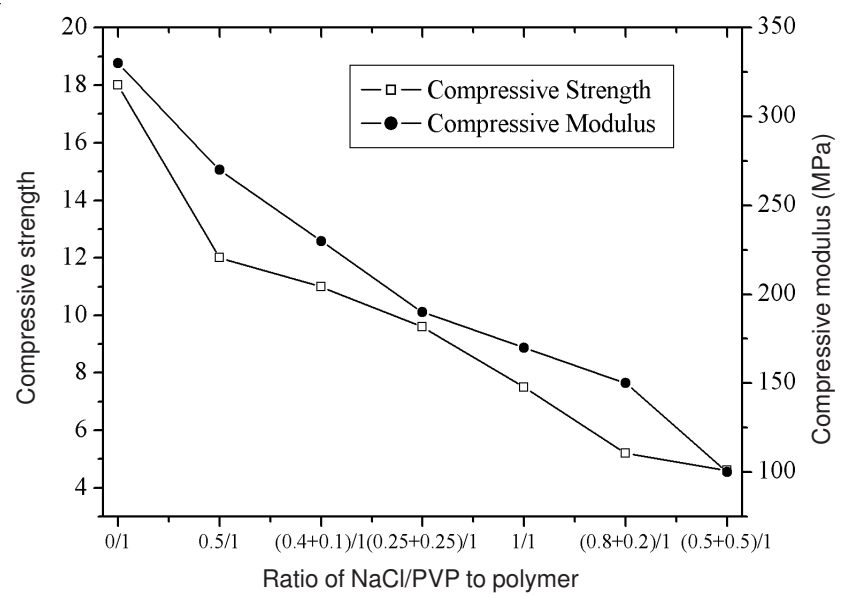

Fig. 8. Compressive strength and compressive modulus of shape memory porous scaffold

In addition, considering Fig. 6 and Fig. 8 simultaneously, we can find that the compressive strength and modulus decreased with increasing of $\mathrm{NaCl} /$ polyvinylpyrrolidone and the decreasing of the weight ratio of porogen to shape memory poly(urethane-urea) (Fig. 8). When the ratio of porogen to shape memory poly(urethane-urea) increased from $0 / 1$ to $(0.5$ $+0.5) / 1$ (scaffold 6), the compressive strength decreased from $19 \mathrm{MP}$ to $5 \mathrm{MP}$, the compressive modulus decreased from 335 MPa to $100 \mathrm{MPa}$. However, the scaffold still keeps the appropriate mechanical property for bone repair since the minimum compressive modulus is $100 \mathrm{MPa}$, which is at the scope of Young's modulus of canellous bone (0.05-0.5 GPa). Upon the above facts, we can presume that the porosity has an important effect on the mechanical property of the porous scaffold.

The scaffolds have appropriate compressive property, since the similar modulus to the natural bone. Literature ${ }^{14}$ indicated that an important with high modulus can cause severe stress concentration, namely load shielding from a natural bone, which may weaken the bone and deteriorate the implant/ bone interface.
Moreover, Fig. 5 is the SEM of two kinds of porous poly (urethane-urea) scaffold, from which we can find that the shape memory poly(urethane-urea) scaffold from emulsion method has compact structure and thick wall, which maybe the main factor of the better mechanical property.

Shape memory performance: Fig. 9 showed the shape fixation and recovery rate of scaffolds. We could clearly see that porous shape memory poly(urethane-urea) scaffold still has great shape memory property $\left(R_{f}, R_{r}\right)$, however, that is lower than poly(urethane-urea). Considering Figs. 6 and 9 simultaneously, we can find that the shape recovery rate $\left(R_{r}\right)$ decreases, from 99 to $54 \%$, with increasing of porosity from 0 to $72 \%$, while pore size from 0 to $80 \mu \mathrm{m}$. The results indicated that the pore has an important role in the shape memory performance of shape memory poly(urethane-urea), especially the bigger pore and high porosity result in the significant decrease of the shape memory performance. The result mainly attributed to change of thermodynamics of shape memory poly(urethane-urea) and the pore structure.

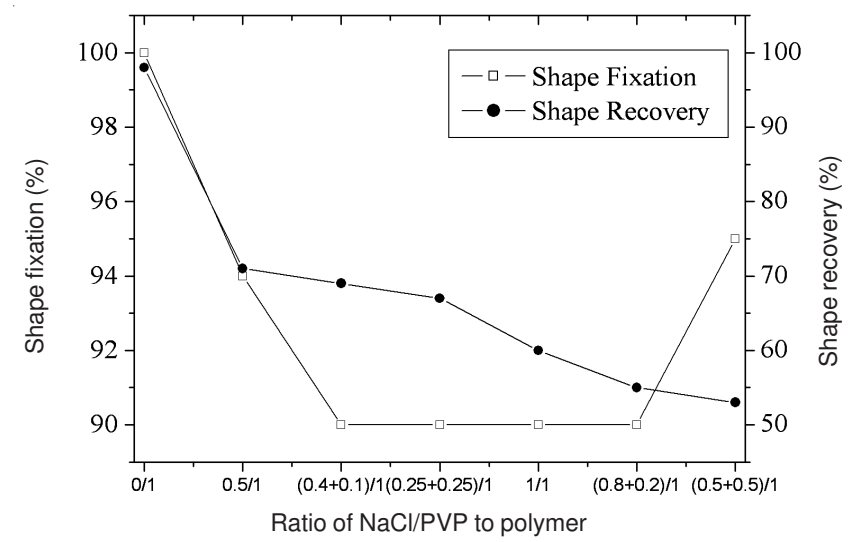

Fig. 9. Shape fixation and shape recovery of shape memory porous scaffold Note: The weight ratio of porogen to SMPUU of scaffolds are 1:1 or $0.5: 1$; When the weight of SMPUU is $1 \mathrm{~g}$, the content of $\mathrm{NaCl} /$ PVP is $0.5 \mathrm{~g}$ or $1 \mathrm{~g}$. The content of NaCl/PVP is $0.5 \mathrm{~g}$ in Scaffold $1 \sim 3$, while $1 \mathrm{~g}$ in Scaffold $4 \sim 6$. We listed the ratio of $\mathrm{NaCl} / \mathrm{PVP}$ as follows: Scaffold 1: ratio of NaCl/PVP is 0.5/0; Scaffold 2: ratio of $\mathrm{NaCl} / \mathrm{PVP}$ is $0.4 / 0.1$; Scaffold 3: ratio of $\mathrm{NaCl} / \mathrm{PVP}$ is $0.25 / 0.25$; Scaffold 4: ratio of $\mathrm{NaCl} / \mathrm{PVP}$ is $1.0 / 0$; Scaffold 5: ratio of $\mathrm{NaCl} /$ PVP is $0.8 / 0.2$; Scaffold 6: ratio of $\mathrm{NaCl} / \mathrm{PVP}$ is $0.5 / 0.5$

Biodegradable poly(urethane-urea) shape memory poly(urethane-urea) composed of two segments (hard and soft segment) and showed phase separation due to the thermodynamic incompatibility of two segments. The soft segment and hard segment show the different thermal properties, including the glass transition temperature, so they played the supporting role and shape memory role, respectively at the specific temperature. By variation of the soft segment component, using different diisocyanates and diol or diamine as the chain extender, the properties of the material can be altered ${ }^{15,16}$. Poly (urethane-urea), a chain extended by diamine, contains a large of urea group in the hard segment and the hydrogen bonding is stronger than that of urethane linkage due to the two-CONHgroups in urea ${ }^{17}$. Since one of the driving forces for phase separation is strong hydrogen bonding between urethane and urea groups ${ }^{18,19}$, the urea groups will produce the higher bond strength and a higher driving force for phase separation. As a 
result, it would result in increasing extent of phase separation, which significantly facilitates the shape memory behaviours of shape memory poly(urethane-urea) ${ }^{3,20}$. For the shape memory porous scaffold, the shape memory performance must be influenced by the porosity and the pore size, which may act as the important factor. Moreover, when the shape of porous shape memory poly(urethane-urea) changed from original shape to temporary shape, the pore will change from open to close, so the integrated structure of porous shape memory poly(urethane-urea) changed, the shape fixation rate and shape recovery rate would be affected.

\section{Conclusion}

In the paper, we successfully fabricated the porous shape memory poly(urethane-urea) by a novel emulsion method. The porous structure had significant effects on the shape memory properties and mechanical properties of shape memory poly(urethane-urea). The shape recovery rate and compressive strength, compressive modulus decreased evident. The porous shape memory poly(urethane-urea) scaffolds have these advantages, e.g. excellent shape memory effect, satisfactory mechanical properties, biodegradation and the special porous structure. The special small pore structure of porous shape memory poly(urethane-urea) provided favourable environment for blood supply and energy supply. The shape memory performance can play a significant role in bone repair, since the porous shape memory poly(urethane-urea) scaffold can fill the vacancy, when it recovered to original shape, which can eliminate the energy barrier during the growth of osteoblast for bone repair. The study of bone repair with the porous scaffold will be reported in future paper.

\section{ACKNOWLEDGEMENTS}

The authors gratefully acknowledged the financial support from the "Eleven-Five" National Science and Technology Support Program of China (2006BA103B04) and Natural Science Foundation of Chongqing (CSTC 2008AB0027) and the Postdoctoral special funding of Chongqing (201102009).

\section{REFERENCES}

1. F.E. Feninat, G. Laroche, M. Fiset and D. Mantovani, Adv. Eng. Mater, 4, 91 (2002).

2. M. Behl and A. Lendlein, Mater. Today, 10, 20 (2007).

3. A. Lendlein and R. Langer, Science, 296, 1673 (2002).

4. A. Alteheld, Y. Feng, S. Kelch and A. Lendlein, Angew. Chem. Int. Ed., 44, 1188 (2005).

5. W.S. Wang, P. Ping, X.S. Chen and X.B. Jing, Eur. Polym. J., 214, 1240 (2006).

6. Q.H. Meng, J.L. Hu, Y. Zhu, J. Lu and Y. Liu, J. Appl. Polym. Sci., 106, 2515 (2007).

7. T. Musumeci, C.A. Ventura, I. Giannone, B. Ruozi, L. Montenegro, R. Pignatello and G. Puglisi, Int. J. Pharm., 325, 172 (2006).

8. Z.X. Zhou, X.L. Wang and Y.Z. Wang, Polym. Int., 55, 383 (2006).

9. Y.F. Luo, Y.L. Wang, X.F. Niu, J. Pan and L.P. Shi, Chinese Chem. Lett., 15, 521 (2004).

10. G.M. Calori, M. Philips, S. Jeetle, L. Tagliabue and P.V. Giannoudis, Injury, 39S2, S59 (2008).

11. M. Panagiotis, Injury, 36S, S30 (2005).

12. P.N. Soucacos, Z. Dailiana, A.E. Beris and E.A. Johnson, Injury, 37S, S41 (2006).

13. A. Biasibetti, D. Aloi, G.D. Gregorio, A. Masse and C. Salomone, Injury, 36S, S45 (2005).

14. C.L. Chu, C.Y. Chung, P.H. Lin and S.D. Wang, Mater. Sci. Eng. A, 366, 114 (2004).

15. E.M. Christenson, J.M. Anderson, A. Hiltner and E. Baer, Polymer, 46, $11744(2005)$

16. B.C. Chun, T.K. Cho and Y.C. Chung, Eur. Polym. J., 42, 3367 (2006).

17. E. Yilgor and I. Yilgor, Polymer, 42, 7953 (2001).

18. H.S. Lee, Y.K. Wang and S.L. Hsu, Macromolecules, 20, 2089 (1987).

19. N. Luo, D.N. Wang and S.K. Yang, Macromolecules, 30, 4405 (1997).

20. P. Ping, W.S. Wang, X.S. Chen and X.B. Jing, J. Polym. Sci. Polym. Phys., 45, 557 (2007) 